EESTI NSV TEADUSTE AKADEEMIA TOIMETISED, 30. KOIDË

GEOLOOGIA. 1981, NR. 3

ИЗВЕСТИЯ АКАДЕМИИ НАУК ЭСТОНСКОИ ССР. ТОМ 30 ГЕОЛОГИЯ. 1981, № 3

\title{
РАСПРЕДЕЛЕНИЕ МИКРОЭЛЕМЕНТОВ В КАРБОНАТНЫХ ПОРОДАХ ОРДОВИКА И СИЛУРА ЭСТОНИИ
}

В предыдущем сообщении (Вингисаар и др., 1979) были обобщены данные о массовом геохимическом материале по карбонатным породам Эстонии. В настоящей работе приведены уточненные данные о содержании микроэлементов в породах ордовика и силура Эстонии (таблица) и дана характеристика их распределения в зависимости от состава пород. Данные незначительно отличаются от опубликованных ранее (Вингисаар и др., 1979, табл. 2), за исключением содержаний фтора, которые в результате систематической ошибки лаборатории оказались заниженными в $3-5$ раз. Из вычисления средних содержаний были исключены слабо представленные породы девона, что не обусловило заметных изменений в результатах. Вместе с тем с увеличением количества проанализированных проб повысилась обоснованность результатов, в частности по мергелям, глинистым доломитам и домеритам. Более или менее удовлетворительно охарактеризованными оказались, таким образом, все 11 типов карбонатных пород, а также глины (тип 12), не вошедшие в расчет средних данных. (Типы пород выделены по упрощенной классификации, приведенной на рисунке в нижнем правом углу диаграммы.) Отдельно выделяются данные по двум специфическим глинистым породам, залегающим в среднеордовикских породах Эстонии: прослоям метабентонитов (преимущественно из Северо-Западной Эстонии) и остаточным карстовым глинам, замещающим горючий сланец (сланцевый бассейн, северо-восток республики).

При 99\%-ной доверительной вероятности диапазон содержаний микроэлементов в выборках не позволяет разграничивать карбонатные породы на основе средних содержаний малых элементов. Тем не менее выявленные тенденции изменений средних содержаний микроэлементов в разных типах -пород имеют закономерный характер и, несомненно, обусловлены природными факторами. Для наглядности средние содержания на треугольных диаграммах кальцит-доломит-нерастворимый остаток приведены в виде изолиний (рисунок). Для этого в центры классификационных ячеек $1-12$ вынесены соответствующие значения из таблицы и обычной интерполяцией между этими точками (центрами) проведены изолинии. Для удобства технического исполнения точки и. их значения на диаграммах не показаны.

В настоящей статье рассматриваются элементы, обнаруживаемые в карбонатных породах Эстонии полуколичественным спектральным анализом почти постоянно. По характеру изменений эти микроэлементы можно разделить на четыре группы. 


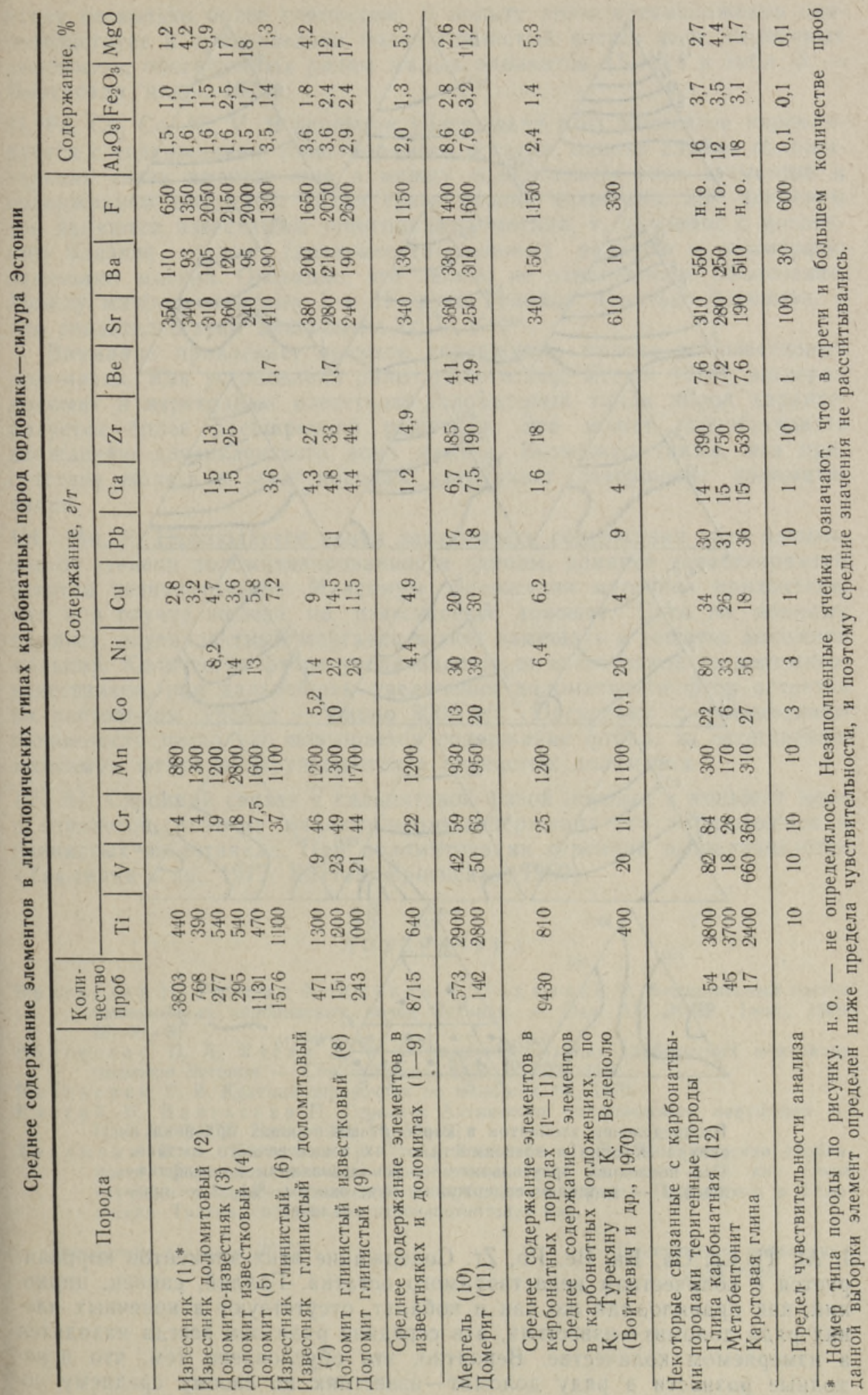



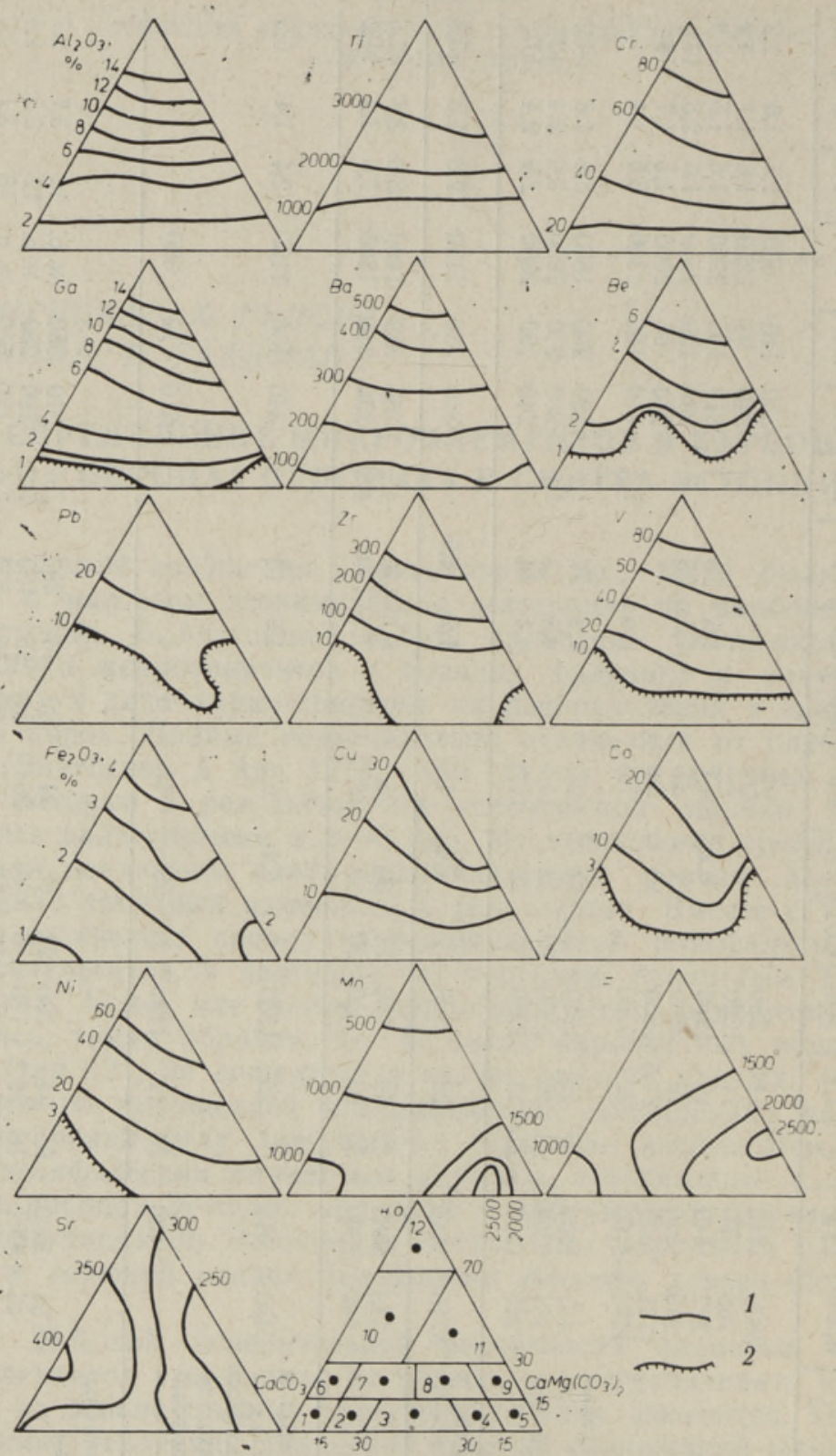

Распределение элементов в карбонатных породах ордовика и силура Эстонии в зависимости от их вещественного состава. (На последнем треугольнике - использованная классификация.) 1 - изолинии содержания $(2 / \tau$; окислы, \%), 2 - предел чувствительности анализа.

I. $\mathrm{Al}, \mathrm{Ti}, \mathrm{Cr}, \mathrm{Ga}, \mathrm{Ba}, \mathrm{Be}, \mathrm{Pb}, \mathrm{Zr}$. Содержание этих элементов коррелируется с количеством нерастворимого остатка. Галлий, свинец, цирконий, как правило, так же как и кобальт, отсутствуют в конечных членах ряда доломит-известняк, а в середине ряда они всегда находятся в измеряемом количестве. Вероятно, это обусловлено тем, что переходные разности в ряду доломит-известняк по своему среднему со- 
ставу несколько более глинистые. В пользу этого предположения свидетельствует и сравнительно более глинистый состав т. н. первичных доломитов, обогащенных рядом малых элементов $\left(\mathrm{S}_{2} \mathrm{rtVs}\right.$ в табл. 3 Вингисаар и др., 1979).

II. $\mathrm{Fe}, \mathrm{Cu}, \mathrm{Co}, \mathrm{Ni}, \mathrm{V}$. В основном содержание этих элементов коррелируется с содержанием нерастворимого остатка, однако слабая положительная связь имеется еще и между содержанием этих элементов и содержанием доломита. Такая связь вполне возможна, ибо элементы эти являются известными «спутниками» магния, т. к. имеют с последним близкие ионные (двухвалентные ионы) радиусы и изоморфно замещают магний. Очевидно, это далеко не единственное объяснение. Между микроэлементами I и II групп граница довольно условная, о чем свидетельствуют диаграммы $\mathrm{Zr}, \mathrm{V}, \mathrm{Ni}$.

Внимание привлекает высокое содержание железа в известковых доломитах. Как установлено ранее (Вингисаар, Утсал, 1978), минерал доломит в переходных известково-доломитовых типах пород характеризуется более расширенной решеткой. Это может способствовать вхождению двухвалентного иона железа. Возможно также, что присутствие железа в этих породах затрудняет завершение доломитизации.

III. Mn, F. Наблюдается явная зависимость содержания этих элементов от степени доломитизированности породы, влияние нерастворимого остатка незначительное. Максимум содержания марганца приходится, как и в случае железа, на известковый доломит. Судя по ионному радиусу, двухвалентный марганец может замещать в решетке доломита кальций. Количество фтора увеличивается от известняков до доломитоизвестняков, при дальнейшем увеличении доломитности фтор остается на постоянном уровне - около 2000 г/T. Поскольку с увеличением глинистости несколько повышается содержание фтора, то естественно, максимум фтора обнаруживается в глинистых доломитах.

IV. Sr. Стронций связан с кальцитовой фазой породы, в меньшей мере с глинистой, поэтому максимальные содержания его наблюдаются в глинистых известняках. При доломитизации стронций выщелачивается (Таалманн и др., 1977; Каттай, Вингисаар, 1980).

\section{ЛИТЕРА Т Р А}

В инги с а а р П., Гулов а Х., Ки й л и Т., Т а а лм анн В. Вещественный состав палеозойских карбонатных пород Эстонии. - Изв. АН ЭССР. Геол., 1979, $28,45-51$.

Вингиса ар П. А., Утсал К. Р. О породообразующих карбонатных минералах палеозоя Эстонии. - Сов. геология, $1978,12,107-115$.

В ой тке в и ч Г. В. Краткий справочник по геохимии. М., 1970.

К а т т а й В., В и нги с а а р П. Строение Ахтмеского тектонического нарушения. Изв. АН ЭССР. Геол., 1980, 29, 55-62.

Т а алм анн ности доломитизированных карбонатных пород Эстония. - B кн.: Опыт изучения вторичных изменений в карбонатных породах Прибалтики и Белоруссии. Таллин, $1977,8-9$. 
P. VINGISAAR, H. GULOVA,

T. KIIPLI, V. TAALMANN

\section{MIKROELEMENTIDE JAOTUS EESTI ORDOVIITSIUMI JA SILURI KARBONAATKIVIMITES}

Kirjutises on täiendatud ja täpsustatud samade autorite 1979. aastal ilmunud artikli andmeid mikroelementide sisaldusest kivimitüüpide kaupa. Kõiki ainelise koostise põhjal eristatud kivimitüüpe on iseloomustatud piisava arvu poolkvantitatiivsete analüüsidega. On kirjeldatud elementide jaotuse seaduspärasusi, mille alusel elemendid on rühmitatud nelja gruppi.

P. VINGISAAR, H. GULOVA,

T. KIIPLI, V. TAALMANN

\section{DISTRIBUTION OF MICROELEMENTS IN ESTONIAN ORDOVICIAN AND SILURIAN CARBONATE ROCKS}

In supplement to the article published in 1979, the authors present additional and more precise data on the distribution of microelements, and fluor in particular, according to rock types, on the basis of semiquantitative spectral analysis. The means of carbonate rocks are represented in the table separately, both in a narrower and wider (together with marls) sense. In the means, the clays occurring only to a small extent in the carbonate rocks, have not been included, viz. ordinary carbonate clays, Middle Ordovician metabentonite (transformed volcanic ash) stratelets and residual clay in karst hollows of shale-kukersite.

The figure illustrates the distribution of some microelements in dependence on the composition of the rock. $\mathrm{Al}, \mathrm{Ti}, \mathrm{Cr}, \mathrm{Ga}, \mathrm{Ba}, \mathrm{Be}, \mathrm{Pb}$ and $\mathrm{Zr}$ depend on the insoluble residue; in case of $\mathrm{Fe}, \mathrm{Cu}, \mathrm{Co}, \mathrm{Ni}, \mathrm{V}$, in addition, a slight connection with dolomite is revealed. The differentiation of the two above-mentioned groups is somewhat conditional owing to transitional elements $(\mathrm{Ni}, \mathrm{V}, \mathrm{Zr})$. In case of $\mathrm{Mn}$ and $\mathrm{F}$, the connection with dolomite is obvious, while $\mathrm{Sr}$ correlates with calcite and to a small extent also with the insoluble residue. 